\title{
Accelerated storage testing of freeze-dried Pseudomonas fluorescens BTP1, BB2 and PI9 strains
}

\author{
Mputu Kanyinda Jean-Noël ${ }^{1,2 \star}$, Destain Jacqueline ${ }^{1}$, Noki Philippe ${ }^{2}$ and Thonart Philippe ${ }^{1}$ \\ ${ }^{1}$ WallonCenter of Industrial Biology (CWBI), Gembloux Agro-Bio Tech, University of Liege, \\ Passage des déportés, 2-5030 Gembloux Belgium. \\ ${ }^{2}$ Department of Chemistry, Faculty of Sciences, University of Kinshasa, BP 190 Kin XI, \\ Kinshasa/ Democratic Republic of the Congo. \\ Accepted 20 November, 2012
}

\begin{abstract}
Freeze-dried cultures of Pseudomonas fluorescens are used in agriculture and microbiological industry. However, $P$. fluorescens is very susceptible to damage during freeze-drying and subsequent storage and it would be useful to increase culture viability during storage. The viability of freeze-dried $P$. fluorescens strains (BTP1, PI9 and BB2) was evaluated by using the Arrhenius model. This model was described by measuring the reaction rate constants ( $D$ or $k$ ) and temperature sensitivity of rate constant ( $z$ or Ea). The freeze-dried $P$. fluorescens strains were stored in glass tubes at 60,37 and $4^{\circ} \mathrm{C}$ for $\mathbf{8} \mathrm{h}, \mathbf{2 8}$ days and two months, respectively. D value decreased or $k$ increased with an increase of the storage temperature. By comparing their decimal reduction time (D), we observed that BB2 strain was more resistant than BTP1 and PI9 at 37 and $60^{\circ} \mathrm{C}$. The activation energy of all $P$. fluorescens strains were not significantly different and thermal inactivation may occur by the same mechanism. Thus, it was possible to compare rate constants of survival for the freeze-dried $\boldsymbol{P}$. fluorescens strains. These results will be useful to the development of improved reference materials and samples held in culture collections.
\end{abstract}

Key words: Arrhenius model, accelerated storage testing (AST), freeze-drying, storage stability.

\section{INTRODUCTION}

Freeze drying is a more effective and gentle method to dry and preserve organisms compared to spray drying or fluidizing. It involves freezing the sample and then removing the water under vacuum through sublimation (Portner et al., 2007). To develop this methodology further, it is therefore important to identify potential hazards and to perform accurate quantitative assessments of constraints, eventually by using probabilistic modelling approaches (Achour et al., 2001).

Accelerated storage testing (AST) is a widely used

*Corresponding author. E-mail:kanyinda2004@googlemail.com.

Abbreviations: AST, Accelerated storage testing; CWBI, Wallon Center of Industrial Biology; $\mathbf{E}_{\mathbf{a}}$, activation energy; $\mathbf{D}$, decimal reduction time. method for the prediction of storage stability, storage quality and estimation of shelf-life of bacterial products (An-Erl King et al., 1998; Hernández et al., 2006; Hernandez et al., 2009). Such tests are performed by incubating the samples at temperatures higher than the usual storage temperature. Thus, data obtained under accelerated tests are used for performing extrapolation studies and prediction of the real-time behaviour. One disadvantage of this approach is that it considers only the assessment of viable cells, while the residual water content is omitted (Hernandez et al., 2009). The Arrhenius equation is the most common and generally valid assumption for the temperature-dependence of the deterioration rate. By means of the Arrhenius relationship, the stability of freeze-dried bacteria was successfully predicted using the accelerated storage test method (An-Erl King et al., 1998; Ziadi et al., 2005; Yao 
et al., 2008; Aguirre et al., 2009). AST can be also used to study the stability of freeze-dried bacteria. Supportive work was previously reported (An-Erl King et al., 1998; Achour et al., 2001; Ziadi et al., 2005; Hernández et al., 2006; Aguirre et al., 2009). The effect of different temperature on the survival of Gram positive bacteria was studied. The applicability of the Arrhenius method in studying and predicting the survival loss rate of the strains during storage may be applicable.

In this model, resistance to heat is described by two parameters: $D$ and $z$. $D$ is the time needed to reduce viable cell numbers by one log unit at a specified temperature, and $z$ is the temperature change needed to bring about a tenfold change in $\mathrm{D}$. Thermal inactivation of microorganisms may also be described by methods based on chemical reaction kinetics (Yao et al., 2008). The Arrhenius equation that is usually employed describes the temperature dependence of the rate constant of inactivation $(k)$, in which the key parameter is the activation energy $\left(E_{a}\right)$. Using the Arrhenius model, it has shown that stability of freeze-dried lactic acid bacteria stored at low temperature may be quantitatively predicted on the results of short-term degradation studies at higher temperatures (Achour et al., 2001; Yao et al., 2008). Furthermore, the physicochemical state of freezedried bacteria was well correlated to temperature (Hutchinson, 2004). However, z-value and Arrhenius models are useful aids in the evaluation of freeze-dried bacteria stability during storage (Achour et al., 2001; Tsen et al., 2007).

The aim of the present work was to study how temperature influences survival of $P$. fluorescens strains freeze-dried during storage by using the Arrhenius model. To do this, we subjected three freeze-dried $P$. fluorescens strains to mortality accelerated test to determine their decimal reduction time (D) and activation energy (Ea).

\section{MATERIALS AND METHODS}

\section{Strains and pre-culture conditions}

The strains used in our study were $P$. fluorescens BTP1 of Wallon Center of Industrial Biology laboratory (CWBI) (Ongena, 1996; Mputu Kanyinda et al., 2012) and P. fluorescens (PI9 and BB2) from Algeria to Saad Dahlab of Blida University. The King B agar (20 mg of casein peptone, $1.5 \mathrm{~g}$ of anhydrous $\mathrm{K}_{2} \mathrm{HPO}_{4}, 1.5 \mathrm{~g}$ of $\mathrm{MgSO}_{4} \cdot \mathrm{H}_{2} \mathrm{O}, 15 \mathrm{~g}$ of glycerol and $12 \mathrm{~g}$ of agar agar) was prepared for the maintenance of $P$. fluorescens strains. A colony from King $B$ agar was inoculated into a pre-culture medium (King $B$ liquid medium) in $250 \mathrm{ml}$ Erlenmeyer flask. This pre-culture was incubated at $30^{\circ} \mathrm{C}$ for $24 \mathrm{~h}$ and inoculated into a $5000 \mathrm{ml}$ Erlenmeyer flask containing $3000 \mathrm{ml}$ King B medium.

\section{Production and freeze-drying}

The strain was grown in $20 \mathrm{~L}$ bioreactor (Biolafite) containing $15 \mathrm{~L}$ of King B medium, for $24 \mathrm{~h}$ and then concentrated 20 times by centrifugation at $4000 \mathrm{rpm}$. The drying operation lasted approximately 46 to $48 \mathrm{~h}$ including two main periods: freezing and sublimation. During freezing, the sample temperature decreased to a value of $-25^{\circ} \mathrm{C}$ and then progressively increased back to $25^{\circ} \mathrm{C}$ at 0.9 mbar pressures. Cells were freeze-dried in a Low freeze-drier (LOUW KOELTECHNIEK BVBA) and stored in glass tube (Yao et al., 2008).

\section{Packaging and storage}

Samples of the freeze-dried $P$. fluorescens were stored in glass tube at 60,37 and $4^{\circ} \mathrm{C}$. For each temperature, the dried samples ( 1 g) were rehydrated in $9 \mathrm{ml}$ of peptone water solution, and sequential dilutions were prepared (Palmfeldt et al., 2003; Santivarangkna et al., 2007). The resulting colonies from samples taken during storage were counted on solid King B medium, and the number of viable cells was measured (Tsen et al., 2007).

\section{Thermal treatment}

Freeze-dried pellet was stored in glass tube for accelerated storage test at 60 and $37^{\circ} \mathrm{C}$. At $60^{\circ} \mathrm{C}$, sample was removed at $2 \mathrm{~h}$ intervals for $10 \mathrm{~h}$ of exposure; at $37^{\circ} \mathrm{C}$, sample was removed at seven days intervals for 28 days of exposure. Freeze-dried sample was also stored at $4^{\circ} \mathrm{C}$ to determine the number of viable cells each 15 days during two months. Kinetics parameters (z-value, activation energy, decimal reduction time and the rate constant of temperature) were determined by the method as described by (Mottar, 1984; Yao et al., 2008; Hernandez et al., 2009).

\section{Kinetics parameters}

For an irreversible first-order reaction at constant temperature, the time dependent kinetic parameter can be expressed as the D-value as followed:

$$
\log N=\log N_{0}-\frac{\mathrm{t}}{D}
$$

The $z$-value represents a temperature range between which $D$ value changes 10 -folds and can be calculated from the $D$ values as shown (1):

$\log D=\log D^{*}-\frac{T-T^{*}}{z}$

The time dependent kinetic parameter can also be expressed as $\mathrm{k}$, which is inversely related to the decimal reduction time (D) as followed:

$\mathrm{k}=2, \frac{303}{\mathrm{D}}$

The rate constant of temperature can be expressed by the Arrhenius model:

$\mathrm{k}=\mathrm{k}^{*} \mathrm{e}^{-\frac{\mathrm{Ea}}{\mathrm{RT}}}$

Where, $\mathrm{k}$ is the rate constant at the $\mathrm{T}$ temperature, $\mathrm{k}^{*}$ is the preexponential term,

$E_{a}$ is the activation energy of the degradation reaction and $R$ is the ideal gas constant.

\section{Statistical analysis}

Data from three replications were analysed by using analysis of 
Table 1. Decimal reduction time (D) or rate constant $(\mathrm{k})$ for freeze-dried $P$. fluorescens strains.

\begin{tabular}{cccccc}
\hline $\boldsymbol{P}$. fluorescens strain & Storage $\left({ }^{\circ} \mathbf{C}\right)$ & $\mathbf{D}(\mathbf{h})$ & $\mathbf{k}\left(\mathbf{S}^{-1}\right)$ & $\mathbf{E}_{\mathbf{a}}\left(\mathbf{k j m o l} \mathbf{l}^{-1}\right)$ & $\mathbf{z}\left({ }^{\circ} \mathbf{C}\right)$ \\
\hline \multirow{2}{*}{ BTP1 } & 4 & 1200 & 0.0019 & & $32.0 \pm 1.1$ \\
& 37 & 56 & 0.021 & 6.1 & \\
& 60 & 1.4 & 1.67 & & \\
& 4 & 1000 & 0.0023 & & \\
PI9 & 37 & 64 & 0.036 & 7.0 & $49.3 \pm 3.5$ \\
& 60 & 1.4 & 1.69 & & \\
& 4 & 3000 & 0.0008 & & \\
BB2 & 37 & 109.3 & 0.021 & 8.4 & $27.1 \pm 3.5$ \\
& 60 & 1.3 & 1.3 & & \\
\hline
\end{tabular}

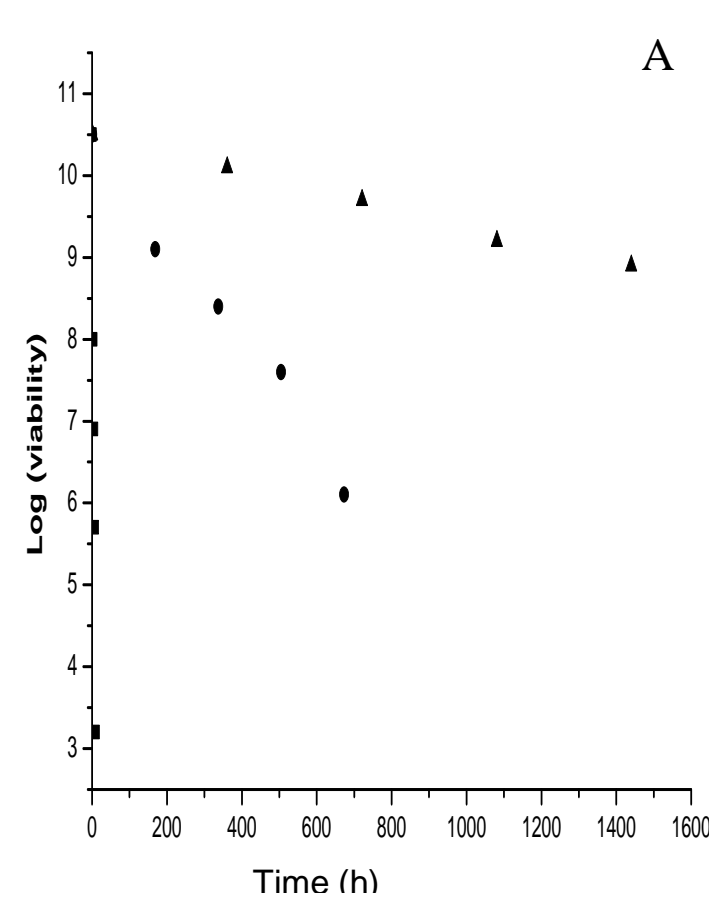

A

B

Figure 1. Thermal mortality curves of freeze-dried $P$. fluorescens strains $(\mathbf{A}) \mathrm{BTP1},(\mathrm{B}) \mathrm{PI9},(\mathbf{C}) \mathrm{BB} 2$ at $4^{\circ} \mathrm{C}(\boldsymbol{\Delta})$, $37^{\circ} \mathrm{C}(\bullet)$ and $60^{\circ} \mathrm{C}(\boldsymbol{\bullet})$. Each point represents the mean of tree counts.

variance to determine if significant differences $(P \leq 0.05)$ existed between mean values.

\section{RESULTS AND DISCUSSION}

The stability of freeze-dried bacteria largely depends on the storage temperature. In order to identify with time some parameters related to conservation of freezedrying $P$. fluorescens strains, we used the Arrhenius theory and the value of $z$ at 60,37 and $4^{\circ} \mathrm{C}$ (Yao et al., 2008). Viable cell counts in glass tubes stored at $60^{\circ} \mathrm{C}$ for $8 \mathrm{~h}$ declined too rapidly to be monitored, and demonstrated that $P$. fluorescens strains BTP1, BB2 and
PI9 are very sensitive to elevated temperature. At 4 and $37^{\circ} \mathrm{C}$, P. fluorescens (BTP1, BB2, PI9) survived; with far the best survival at $4^{\circ} \mathrm{C}$. Figure 1 shows the thermal mortality curves of freeze-dried $P$. fluorescens BTP1 at 60,37 and $4^{\circ} \mathrm{C}$. At each storage temperature, linear regressions were conducted for $\log _{10}$ (viability) in function of storage time according to Equation (1). For example, $P$. fluorescens BTP1 decreased from 10.30 $\log _{10}$ to $4.5 \log _{10}$ at $60^{\circ} \mathrm{C}$ after $8 \mathrm{~h}$ storage, to $5.7 \log _{10}$ after 28 days storage at $37^{\circ} \mathrm{C}$ and to $9.2 \log _{10}$ after 60 days storage at $4^{\circ} \mathrm{C}$.

The present results basically confirm literature data (An-Erl King et al., 1998; Achour et al., 2001; Picot and 
16190 Afr. J. Biotechnol.

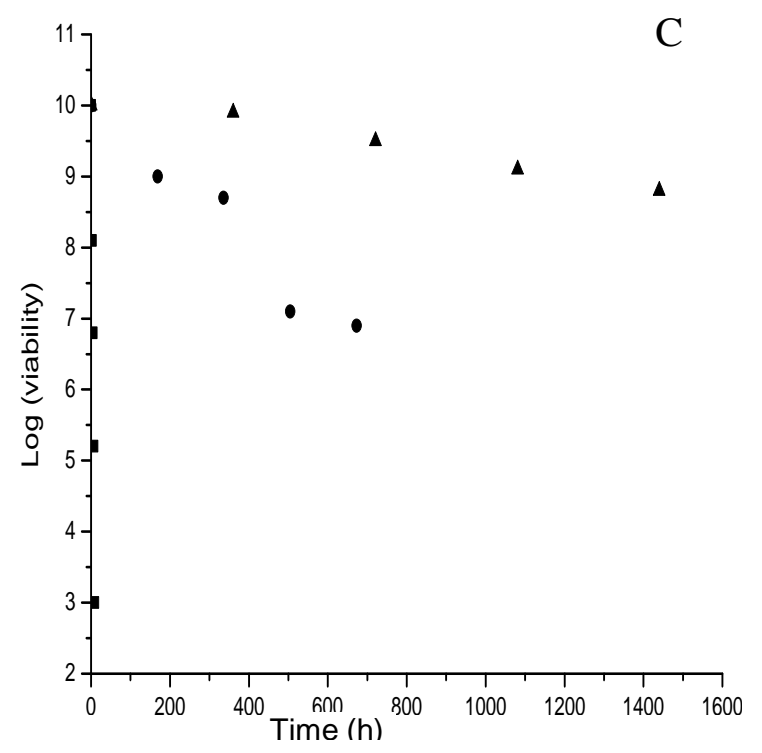

Figure 1. Continued.
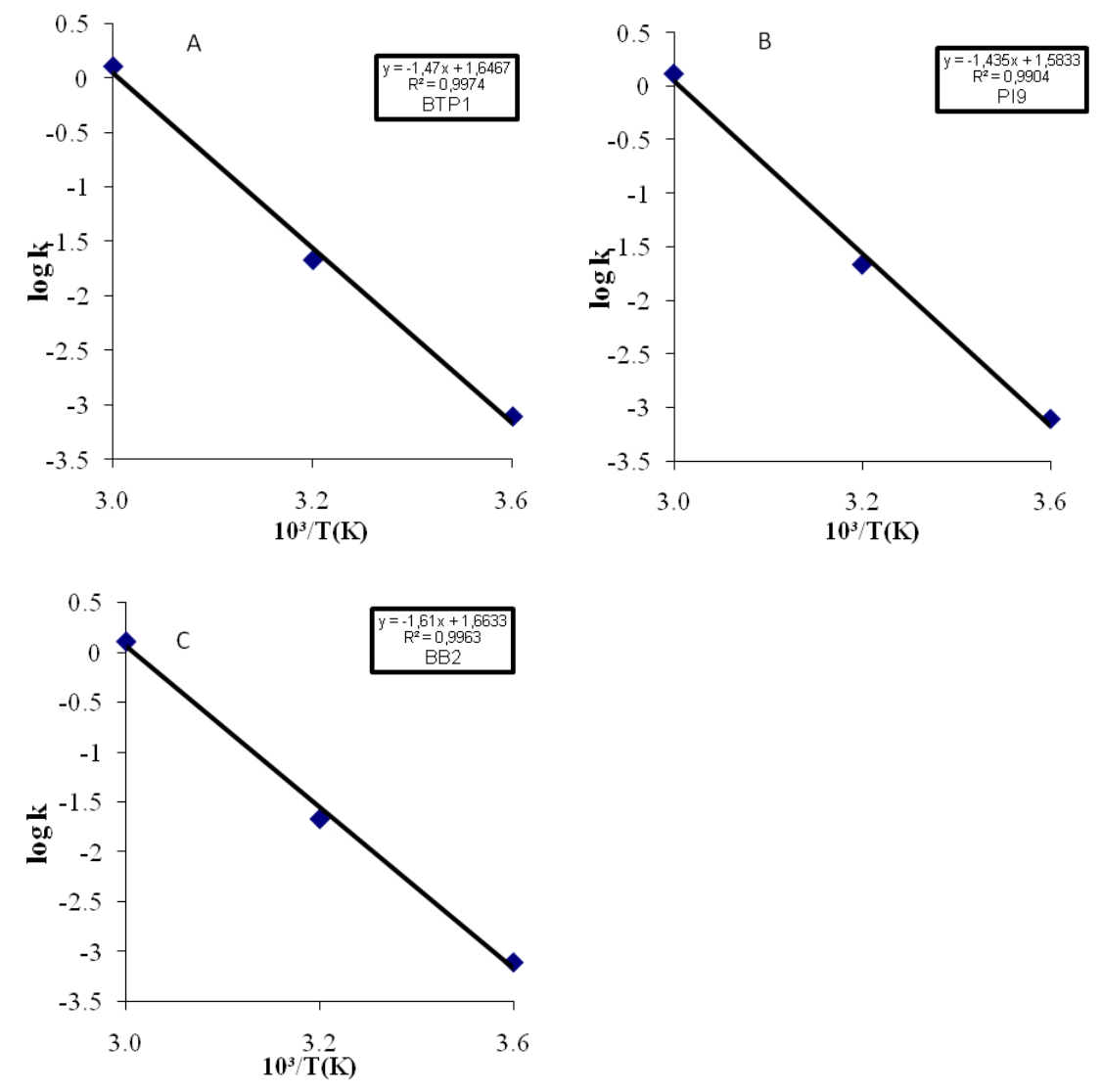

Figure 2. Determination of activation energy (Ea) of freeze-drier $P$. fluorescens strains. $\bullet$ BTP1; $\mathbf{m}, \mathrm{BB} 2 ; \boldsymbol{\Delta}, \mathrm{PI9}$.

Lacroix, 2003; Ziadi et al., 2005). Strain BB2 performs better than BTP1 and PI9 at 37 and $60^{\circ} \mathrm{C}$. Some work demonstrated, that experimental determination of bacterial survival at higher temperatures can be successfully used to predict bacterial survival for lower temperature (Achour et al., 2001; Hernández et al., 2006; Ziadi et al., 2005; Yao et al., 2008). Figure 2 shows the survival rate curves of $P$. fluorescens strains. 
The data obtained were used to calculate decimal reduction times (D), inactivation constant (k), activation energy and value of thermal resistance ( $\mathrm{z}$ ) according to equations 2 to 4 . $z$ is the change in temperature required to obtain a tenfold increase or decrease to a tenth of the value $D$, for our strains (BTP1, BB2, PI9), $z$ value obtained were $32.04 \pm 1,1^{\circ} \mathrm{C} ; 27.10 \pm 1 ; 3^{\circ} \mathrm{C}$ and $49.3 \pm 3$, $5^{\circ} \mathrm{C}$, respectively. The activation energy values $(\mathrm{Kj} / \mathrm{mol})$ for the degradation process of the powders stored at glass tube were 6.1 for BTP1, 8.4 for BB2 and 7.0 for $\mathrm{PI9}$. The kinetic parameters $\mathrm{k}$ and $\mathrm{D}$ calculated from equations (1) and (4), respectively show that the decrease in decimal reduction time (D) or the increase of $\mathrm{k}$ temperature dependent (Yao et al., 2008).

The $E_{a}$ and $z$ value are inter-related. $D$ and $z$ values were experimentally obtained as given in Table 1 and used to design the heat treatments in order to obtain several inactivation intensities. Increasing the storage temperature causes an increase in cell death, and this shows that the freeze-dried powders of $P$. fluorescens strains does not keep viability for very long time during storage at temperatures above $30^{\circ} \mathrm{C}$.

\section{Conclusion}

Freeze-drying is a useful technology for drying $P$. fluorescens strains. Our results demonstrate that the $z-$ value or Arrhenius models could be used to predict storage stability of freeze-dried $P$. fluorescens at various temperatures. The $\mathrm{R}^{2}$ value (Figure 2 ) close to unity is an indication of the applicability of the Arrhenius law, indicating an exponential effect of the storage temperature on the survival rate loss of the studying and predicting the survival rate loss of the strains during storage. Storage temperature at $60^{\circ} \mathrm{C}$ had a destructive effect on the viability of the freeze-dried bacteria of all three tested strains.

\section{ACKNOWLEDGEMENT}

We thank the Belgium Technical Cooperation (BTC) for the financial assistance.

\section{REFERENCES}

Achour M, Mtimet N, Cornelius C, Zgouli S, Mahjoub A, Thonart P, Hamdi M. (2001). Application of the accelerated shelf life testing method (ASLT) to study the survival rates of freeze-dried Lactococcus starter cultures. J. Chem. Technol. Biotechnol. 76:624628.
Aguirre JS, Pin C, Rodriguez MR, García de Fernando GD (2009). Analysis of the Variability in the Number of Viable Bacteria after Mild Heat Treatment of Food. Appl. Environ. Microbiol. 75:6992-6997.

An-Erl King, V, Haur-Jie Lin, Liu, C-F (1998). Accelerated storage testing of freeze-dried and controlled low-temperature vacuum dehydrated Lactobacillus acidophilus. J. Gen. Appl. Microbiol. 44:161-165.

Hernández A, Weekers F, Mena J, Borroto C, Thonart P (2006). Freeze-drying of the biocontrol agent Tsukamurella paurometabola C-924 Predicted stability of formulated powders. Ind. Biotechnol. 2:209-212.

Hernandez A, Zamora J, Gonzalez N, Salazar E, Sanchez MDC (2009). Anhydrobiosis quotient: a novel approach to evaluate stability in desiccated bacterial cells. J. Appl. Microbiol. 107:436-442.

Hutchinson TP (2004). Regression and the hypothesis of accelerated life. J. Chem. Technol. Biotechnol. 79:44-48.

Mottar J (1984). Heat resistant proteinases from bacterial origin in milk. Le Lait. 64:356-367.

Mputu Kanyinda JN, Pierart C, Weekers F, Destain J, Thonart P (2012). Impact of protective compounds on the viability, physiological state and lipid degradation of freeze-dried Pseudomonas fluorescens BTP1 during storage. Int. J. Biotech. Biochem. 8:17-26.

Ongena M (1996). Etude de sidérophores de Pseudomonas fluorescents en relation avec la lutte biologique, Université de liège, Liège, Belgique.

Palmfeldt J, Radström P, Hahn-Hägerdal B (2003). Optimisation of initial cell concentration enhances freeze-drying tolerance of Pseudomonas chlororaphis. Cryobiology 47:21-29.

Picot A, Lacroix C (2003). Effects of micronization on viability andthermotolerance of probiotic freeze-dried cultures. Int. Dairy $\mathrm{J}$. 13:455-462.

Portner DC, Leuschner R G K, Murray B S (2007). Optimising the viability during storage of freeze-dried cell preparations of Campylobacter jejuni. Cryobiology 54:265-270.

Santivarangkna C, Kulozik U, Foerst P (2007). Alternative Drying Processes for the Industrial Preservation of Lactic Acid Starter Cultures. Biotechnol. Prog. 23:302-315.

Tsen J H, Lin YP, Huang HY, King V AE (2007). Accelerated storage testing of freeze-dried immobilized Lactobacillus Acidophilusfermented banana media. J. Process. Preserv. 31:688-701.

Yao AA, Bera F, Franz C, Holzapfel W, Thonart P (2008). Survival Rate Analysis of Freeze-Dried Lactic Acid Bacteria Using the Arrhenius and z-Value Models. J. Food Prot. 71:431-434.

Ziadi M, Touhami Y, Achour M, Thonart P, Hamdia M (2005). The effect of heat stress on freeze-drying and conservation of Lactococcus. Biochem. Eng. J. 24:141-145. 